\title{
In vitro evaluation of the efficacy of two bleaching procedures
}

\author{
Gonzalo Llambés ${ }^{1}$, Carmen Llena ${ }^{2,3}$, José Amengual ${ }^{1}$, Leopoldo Forner ${ }^{2}$
}

\footnotetext{
${ }^{1}$ Associate Professor. Department of Stomatology. University of Valencia (Spain)

${ }^{2}$ Professor. Department of Stomatology. University of Valencia (Spain)

${ }^{3}$ Dentist. Valencian Health Service. Valencia (Spain)
}

Correspondence:

Departamento de Estomatología,

Universitat de València

C. Gascó Oliag $n^{\circ} 1$,

46010 Valencia (Spain)

forner@uv.es

\author{
Llambés G, Llena C, Amengual J, Forner L. In vitro evaluation of the effi- \\ cacy of two bleaching procedures. Med Oral Patol Oral Cir Bucal. 2011 \\ Sep 1;16 (6):e845-51. \\ http://www.medicinaoral.com/medoralfree01/v16i6/medoralv16i6p845.pdf

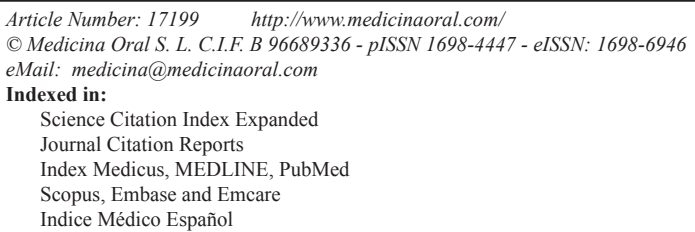

\begin{abstract}
Objective: In vitro comparison of the efficacy of two bleaching procedures, one based on carbamide peroxide (CP) and the other on hydrogen peroxide (HP), simulating clinical conditions.

Study Design: Two groups of 20 teeth in each group were selected. Group A: $22 \%$ CP, one hour a day for 21 consecutive days. Group B: $37.5 \%$ HP, in 2 treatment sessions with an one week interval between each session. At each session the product was applied three successive times for eight minutes. Colour was recorded before treatment, when it was finished and one week after finishing it, with the Vita EasyShade spectrophotometer. CIEL*a*b* and $\Delta \mathrm{E}$ were established at each moment in the study. Intra-group data was compared using the paired t-test and intergroup data with the independent groups t-test. Scores from the Vita Classical guide provided with the device were recorded and the colour improvement percentage was calculated.

Results: In both groups significant whitening was achieved by the end of treatment. Lightness remained significantly high when treatment was finished and one week after in both groups. The percentage of bleaching was significantly higher in group A.

Conclusions: Both 22\% CP and 37.5\% HP were effective for bleaching teeth. Bleaching effect was greater in CP group.
\end{abstract}

Key words: Dental bleaching, hydrogen peroxide, carbamide peroxide, dental whitening, dental colour.

\section{Introduction}

The bleaching process usually uses hydrogen peroxide (HP), either directly or indirectly (via its generation in a carbamide peroxide-CP-gel). There are several methods and approaches described in the literature for bleaching vital teeth, including using different bleaching agents, application times, trade presentations and application ways. In-office tooth bleaching can be performed in two ways: a) dentist-administered bleaching use high concentration hydrogen peroxide -from 35 to $38 \%$ - or carbamide peroxide -from 35 to $40 \%$-, supplemented or not with a light source; b) dentist-supervised bleaching is applied usually with a bleaching tray loaded with high concentrations CP -from 35 to $40 \%$ - that is placed in the 
patient's mouth for $30 \mathrm{~min}$ to 2 hours while the patient is in the dental office (1).

In-office bleaching procedures seem to be an appropriate alternative to home bleaching applications with trays, strips or gels, specially in the case of very severe discolorations, discolorations of single teeth, lack of patient compliance or if a rapid treatment is desired. Inoffice bleaching could also be applied as a kind of boost therapy, thereby initiating the bleaching process, which might be continued afterwards by home-bleaching procedures (2). Most descriptions in the literature of successful applications of in-office bleaching therapies are case reports or studies in which no comparisons to well approved methods, such as home-bleaching procedures, have been done (3). Auschill et al. (4) were able to show that both home-bleaching procedures (10\% CP gel tray application or 5.3\% HP impregnated strips) and inoffice-bleaching with $35 \%$ HP without heat activation may be used to brighten teeth six shades on the vita colour scale. In the in-office procedure this change was achieved after only $3.1 \pm 0.5$ applications of $15 \mathrm{~min}$ each, whereas $31.8 \pm 6.6$ applications of $30 \mathrm{~min}$ each were needed with the strip. 7.1 \pm 1.9 applications for $8 \mathrm{~h}$ each were necessary when using the carbamide peroxide gel.

Professionally supervised at-home tooth bleaching has become a popular method used to treat tooth discoloration. The popularity of this method is related to its quick esthetic improvement, low incidence of side effects and ease of technique with reduced chair time (5). Until recently, the most common and widely accepted at-home tooth whitening method has been the one first proposed by Haywood and Heymann, in which a custom tray with CP is used by the patient for a select number of hours (6). Manufacturers have introduced different concentrations of CP (5\% to $22 \%)$ $(7,8)$ or HP $(3 \%$ to $14 \%)$ for at-home whitening $(9,10)$. In 2006, the American Dental Association (ADA) (11) published a new program guidelines for the acceptance of dentist dispensed at-home tooth bleaching products that assure the safety and efficacy of tray applied $10 \pm 1 \% \mathrm{CP}$ based on published clinical trials. Few controlled clinical trials $(12,13)$ have observed the improved efficacy of at-home whitening when increasing concentration of the bleaching agent. Additionally, an increase in side effects has been detected (12-14).

The available literature is not conclusive over whether higher product concentrations provide better short and medium term results, although there is consensus among most authors that higher concentrations provide favorable results with a shorter application time (4). Furthermore, the use of products with high concentrations of HP increases risks, such as burns to the oral mucosa or hypersensitivityand requires the use of rigorous oral tissues protection procedures such as rubber dam isolation or alternatives such as specially designed light-curing isolating pastes (15).

Based on the above, our study, carried out in vitro, aims to evaluate the bleaching efficacy of two procedures, one based on the use of $22 \% \mathrm{CP}$, and the other based on $37.5 \% \mathrm{HP}$.

\section{Materials and Methods}

For this study, 40 teeth were selected (premolars and molars) all caries free, without structural enamel defects or previous restorative treatments. The teeth had been extracted for periodontal or orthodontic reasons and their initial colour was greater than or equal than B2 (Vita Classical guide - VITA Zahnfabrik, Bad Säckingen, Germany). They were randomly distributed into two groups (A and B) of 20 teeth each. From extraction until use and during the treatment process the teeth were kept in physiological saline solution.

Group A was treated with $22 \%$ carbamide peroxide (Norblanc Home, Normon, Madrid, Spain), a household product, applied in trays for dentist supervised use. In our study it was applied one hour a day for 21 days (in total, 21 hours of treatment). Group B was treated with $37.5 \%$ hydrogen peroxide (Pola Office + , SDI, Bayswater, Victoria, Australia), a chemically activated product for in-office application. Two treatment sessions were carried out with an interval of one week between them. At each session the teeth were given 3 applications lasting eight minutes (a total of 48 minutes of treatment). These are two commons concentrations for at-home and in-office respectively dental bleaching techniques (high concentrations for each kind). A $22 \%$ $\mathrm{CP}$ is equivalent to a $7,3 \% \mathrm{HP}$, as $\mathrm{CP}\left[\mathrm{CO}\left(\mathrm{NH}_{2}\right)_{2} \mathrm{H}_{2} \mathrm{O}_{2}\right]$ breaks down into approximately $3 \% \mathrm{HP}\left(\mathrm{H}_{2} \mathrm{O}_{2}\right)$ and $7 \%$ urea (16). Clinical procedures used are those generally applied for dental bleaching with the mentioned peroxide concentrations (17). To apply the bleaching agents, the teeth were mounted in groups of five teeth, CP was applied with a custom tray like those used in home bleaching treatments.

In orther to make the trays, the 5 teeth were stabilized in a silicone block. An alginate impression was taken and a plaster model was obtained. The labial model teeth surfaces were covered with $1 \mathrm{~mm}$ thick spacer up to 1 mm of the cervical margin. A vacuum forming machine was used to make a $0.8 \mathrm{~mm}$ thick custom tray (17).

HP was placed directly on all teeth surfaces, in a $2 \mathrm{~mm}$ thick layer in order to get enough material to produce active bleaching agent (17).

Tooth colour was recorded using a spectrophotometer (VITA EasyShade -Vita Zahnfabrik, Bad Säckingen, Germany-). In order to standardize the position of colour recording at all times, a custom positioning tray was made for each group of teeth (Fig. 1). The tip of the spectrophotometer was positioned perpendicular 


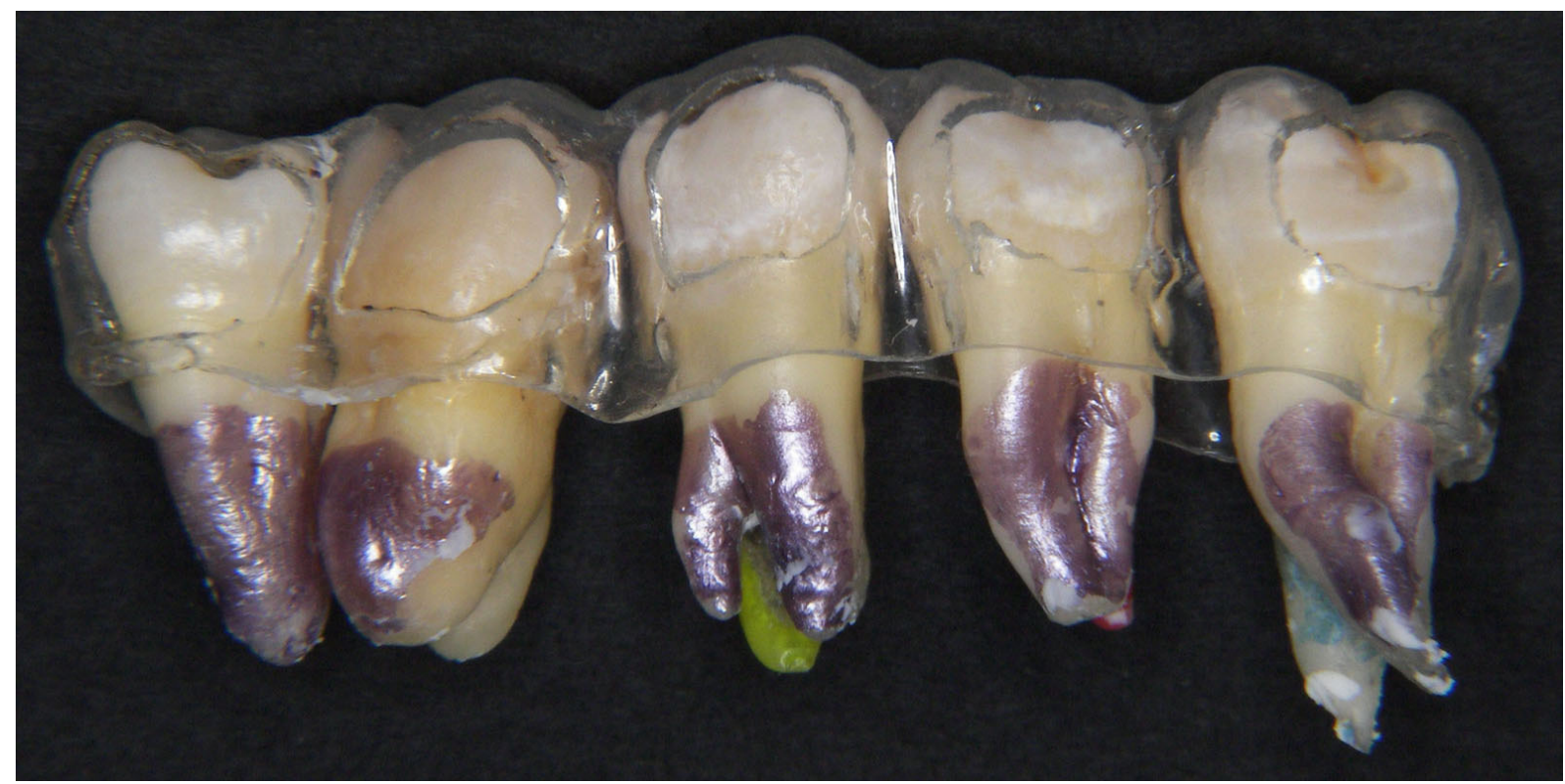

Fig. 1. Custom trays designed for colour measurement.

Table 1. Vita shade colour (From Vita Classical guide) organized by lightness (from the lightest -B1- to the darkest colour -C4-).

\begin{tabular}{|c|c|c|c|c|c|c|c|c|c|c|c|c|c|c|c|c|}
\hline Vita shade guide & B1 & A1 & B2 & D2 & A2 & C1 & C2 & D4 & A3 & D3 & B3 & A3,5 & B4 & C3 & A4 & C4 \\
\hline Scores & 1 & 2 & 3 & 4 & 5 & 6 & 7 & 8 & 9 & 10 & 11 & 12 & 13 & 14 & 15 & 16 \\
\hline
\end{tabular}

to the tooth surface in the space created by the positioning tray. Colour was recorded before beginning of treatment again when treatment finished and lastly, one week after treatment had finished. The value showed by the spectrophotometer was determined in reference to the Vita Classical guide and CIELAB L*, a*, b* scores, both provided by the device. This last system was defined by the International Commission on Illumination in 1967 (18); L* represents the value (lightness or darkness), $a^{*}$ is a measure of redness (positive $a^{*}$ ) or greenness (negative $\left.a^{*}\right) ; b^{*}$ is a measure of yellowness (positive $b^{*}$ ) or blueness (negative $b^{*}$ ). Difference between colour coordinates is calculated as $\Delta \mathrm{E}^{*}=\left[\left(\Delta \mathrm{L}^{*}\right)^{2}\right.$ $\left.+\left(\Delta \mathrm{a}^{*}\right)^{2}+\left(\Delta \mathrm{b}^{*}\right)^{2}\right]^{1 / 2}$. Tooth whitening mainly occurs as a reduction in yellowness (lower $b^{*}$ ) and an increase in lightness (higher L*) (19).

The Vita Classical guide was organized in relation to value -ligthness- (Table 1). The number of shade tab changes for each tooth was determined from the pretreatment situation to the immediate posttreatment situation. Colour was assessed again one week after finishing the treatment. In addition, the bleaching percentage was calculated, taking into account the difference between the initial colour and the maximum bleaching a tooth can achieve, considering that a tooth achieves $100 \%$ improvement in colour when it reaches colour
B1, so for teeth which did not reach B1, the bleaching percentage was determined by calculating a proportion according to the number of shade tab changes.

$L^{*}, a^{*}, b^{*}$ and $\Delta E$ parameters were also compared between the pretreatment situation, end of treatment and one week later.

The data records were checked for normal distribution using the Kolmogorow Smirnov test. Intra-group variables were compared with the paired t-test and intergroup variables using the independent groups t-test. Confidence level for all the analyses was $95 \%(\alpha=0.05)$.

\section{Results}

At the end of treatment (immediately after the last bleaching agent applicaton), $15 \%$ of the specimens in group A showed no bleaching, whereas after one week after the end of the treatment, $100 \%$ of the teeth had experienced some degree of change. In group B, $15 \%$ of the specimens showed no improvement in colour at the end of the treatment. $75 \%$ of the sample showed a bleaching percentage equal to $21 \%$ both at the end of treatment and one week later (Fig. 2).

Table 2 shows the mean values for each of the parameters in each group. It can be seen that in group A, L* lightness increased at the end of treatment and remained high one week after treatment, in both cases with 
Table 2. Comparison of intra-group measurements for $\mathrm{L}^{*}, \mathrm{a}^{*}, \mathrm{~b}^{*}, \Delta \mathrm{E}$, at the start, end and one week after treatment. Comparison of the shade tab changes and bleaching percentage between the end of treatment and one week later.

\begin{tabular}{|c|c|c|c|c|c|c|}
\hline & \multicolumn{3}{|c|}{ Group A (CP) } & \multicolumn{3}{|c|}{ Group B (HP) } \\
\hline & Mean & SD & $\mathrm{p}$ & Mean & SD & $\mathrm{p}$ \\
\hline \multirow{2}{*}{$\begin{array}{ll}\text { L } & \text { Initial } \\
\text { L } & \text { Final }\end{array}$} & 75.66 & 9.41 & \multirow{2}{*}{$<0.001$} & 75.68 & 5.68 & \multirow{2}{*}{$<0.001$} \\
\hline & 94.62 & 6.12 & & 87 & 5.74 & \\
\hline \multirow{2}{*}{$\begin{array}{ll}\text { a } & \text { InitiaI } \\
\text { a } & \text { Final }\end{array}$} & 2.81 & 3.65 & \multirow{2}{*}{$<0.001$} & 3.44 & 2.55 & \multirow{2}{*}{0.821} \\
\hline & .07 & 2.53 & & 3.38 & 2.68 & \\
\hline \multirow{2}{*}{$\begin{array}{ll}\text { b } & \text { InitiaI } \\
\text { b } & \text { Final }\end{array}$} & 36.06 & 6.96 & \multirow{2}{*}{0.531} & 40.21 & 7.31 & \multirow{2}{*}{$<0.001$} \\
\hline & 35.27 & 6.69 & & 44.01 & 8.66 & \\
\hline \multirow{2}{*}{$\begin{array}{l}\text { L Initial } \\
\text { L Week }\end{array}$} & 75.66 & 9.41 & \multirow{2}{*}{$<0.001$} & 75.68 & 5.68 & \multirow{2}{*}{$<0.001$} \\
\hline & 89.16 & 6.53 & & 86.72 & 5.91 & \\
\hline \multirow{2}{*}{$\begin{array}{l}\text { a Initial } \\
\text { a Week }\end{array}$} & 2.81 & 3.65 & \multirow{2}{*}{$<0.001$} & 3.44 & 2.55 & \multirow{2}{*}{$<0.001$} \\
\hline & -1.31 & 1.65 & & 5.59 & 3.03 & \\
\hline \multirow{2}{*}{$\begin{array}{l}\text { b Initial } \\
\text { b Week }\end{array}$} & 36.06 & 6.96 & \multirow{2}{*}{$<0.001$} & 40.21 & 7.31 & \multirow{2}{*}{$<0.001$} \\
\hline & 27.23 & 6.80 & & 47.84 & 6.94 & \\
\hline \multirow{2}{*}{$\begin{array}{l}\text { L Final } \\
\text { L Week }\end{array}$} & 94.62 & 6.12 & \multirow{2}{*}{$<0.001$} & 87 & 5.74 & \multirow{2}{*}{0.747} \\
\hline & 89.16 & 6.53 & & 86.72 & 5.91 & \\
\hline \multirow{2}{*}{$\begin{array}{l}\text { a Final } \\
\text { a Week }\end{array}$} & .07 & 2.53 & \multirow{2}{*}{$<0.001$} & 3.38 & 2.68 & \multirow{2}{*}{$<0.001$} \\
\hline & -1.31 & 1.65 & & 5.59 & 3.03 & \\
\hline \multirow{2}{*}{$\begin{array}{l}\text { b Final } \\
\text { b Week }\end{array}$} & 35.27 & 6.69 & \multirow{2}{*}{$<0.001$} & 44.01 & 8.66 & \multirow{2}{*}{$<0.001$} \\
\hline & 27.23 & 6.80 & & 47.84 & 6.94 & \\
\hline \multirow{2}{*}{$\begin{array}{l}\Delta \text { E Final } \\
\Delta \text { E Week }\end{array}$} & 19.96 & 6.11 & \multirow{2}{*}{$<0.001$} & 12.40 & 3.21 & \multirow{2}{*}{$<0.001$} \\
\hline & 9.85 & 3.95 & & 5.20 & 2.94 & \\
\hline \multirow{2}{*}{$\begin{array}{l}\text { Shade tab changes Final } \\
\text { Shade tab changes Week }\end{array}$} & 5.40 & 3.34 & $0 \Omega 61$ & 2.70 & 1.62 & 0276 \\
\hline & 7.10 & 4.50 & 0.001 & 2.35 & 1.38 & $0.3 / 0$ \\
\hline$\%$ of bleaching Final & 44.65 & 28.99 & 0016 & 20.40 & 14.06 & \\
\hline$\%$ of bleaching Week & 65.10 & 32.99 & 0.016 & 18.60 & 9.23 & \\
\hline
\end{tabular}

HP: hydrogen peroxide, CP: carbamide peroxide. SD: standard deviation.

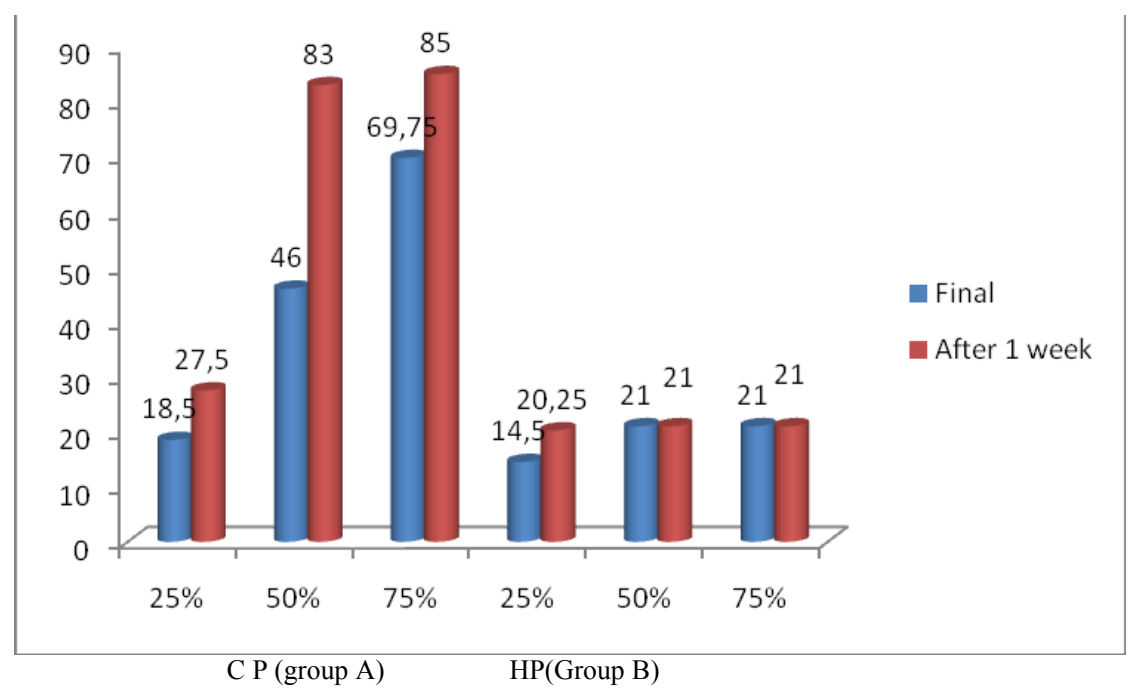

Fig. 2. Bleaching percentage obtained with $\mathrm{CP}$ and $\mathrm{HP}$ at the end of treatment and one week later for sample percentiles 25,50 and 75 . HP: hydrogen peroxide, CP: carbamide peroxide. 
Table 3. Comparison of $\Delta \mathrm{L}^{*}, \Delta \mathrm{a}^{*}, \Delta \mathrm{b}^{*}$ and $\Delta \mathrm{E}$, between start, end and one week after treatment. Comparison of shade tab changes and bleaching percentage between the end of treatment and one week later.

\begin{tabular}{|c|c|c|c|c|}
\hline & Group & Mean & SD & $\mathbf{p}$ \\
\hline \multirow{2}{*}{$\Delta \mathbf{L}^{*}$ Final/Initial } & $\mathrm{A}(\mathrm{CP})$ & 18.96 & 6.08 & \multirow{2}{*}{$<0.001$} \\
\hline & B (HP) & 11.31 & 3.25 & \\
\hline \multirow{2}{*}{$\Delta \mathbf{a} *$ Final/Initial } & $\mathrm{A}(\mathrm{CP})$ & -2.74 & 1.64 & \multirow{2}{*}{$<0.001$} \\
\hline & $\mathrm{B}(\mathrm{HP})$ & -.06 & 1.27 & \\
\hline \multirow{2}{*}{$\Delta \mathbf{b}^{*}$ Final/Initial } & $\mathrm{A}(\mathrm{CP})$ & -.78 & 5.49 & \multirow{2}{*}{0.003} \\
\hline & B (HP) & 3.79 & 3.22 & \\
\hline \multirow{2}{*}{$\Delta \mathbf{L} *$ Week /Initial } & $\mathrm{A}(\mathrm{CP})$ & 13.50 & 5.42 & \multirow{2}{*}{0.116} \\
\hline & B (HP) & 11.04 & 4.17 & \\
\hline \multirow{2}{*}{$\Delta \mathbf{a} *$ Week /Initial } & $\mathrm{A}(\mathrm{CP})$ & -4.12 & 2.39 & \multirow{2}{*}{$<0.001$} \\
\hline & $\mathrm{B}(\mathrm{HP})$ & 2.14 & 1.81 & \\
\hline \multirow{2}{*}{$\Delta \mathbf{b}^{*}$ Week /Initial } & $\mathrm{A}(\mathrm{CP})$ & -8.82 & 4.54 & \multirow{2}{*}{$<0.001$} \\
\hline & $\mathrm{B}(\mathrm{HP})$ & 7.62 & 3.34 & \\
\hline \multirow{2}{*}{$\Delta \mathbf{L} *$ Final/Week } & $\mathrm{A}(\mathrm{CP})$ & 5.46 & 3.30 & \multirow{2}{*}{$<0.001$} \\
\hline & B (HP) & .26 & 3.61 & \\
\hline \multirow{2}{*}{$\Delta \mathbf{a}^{*}$ Final/Week } & $\mathrm{A}(\mathrm{CP})$ & -1.38 & 1.15 & \multirow{2}{*}{$<0.001$} \\
\hline & B (HP) & 2.21 & 1.16 & \\
\hline \multirow{2}{*}{$\Delta \mathbf{b}^{*}$ Final/Week } & $\mathrm{A}(\mathrm{CP})$ & 8.04 & 3.29 & \multirow{2}{*}{$<0.001$} \\
\hline & B (HP) & -3.83 & 3.34 & \\
\hline \multirow{2}{*}{$\Delta \mathbf{E} *$ Final/Week } & $\mathrm{A}(\mathrm{CP})$ & 10.10 & 5.74 & \multirow{2}{*}{0.090} \\
\hline & $\mathrm{B}(\mathrm{HP})$ & 7.09 & 4.79 & \\
\hline \multirow{2}{*}{ Shade tab changes week /Final } & $\mathrm{A}(\mathrm{CP})$ & 1.70 & 3.81 & \multirow{2}{*}{0.035} \\
\hline & $\mathrm{B}(\mathrm{HP})$ & -.35 & 1.72 & \\
\hline \multirow{2}{*}{$\%$ of bleaching Week/ Final } & $\mathrm{A}(\mathrm{CP})$ & 20.45 & 34.47 & \multirow{2}{*}{0.012} \\
\hline & B (HP) & -1.80 & 15.40 & \\
\hline
\end{tabular}

HP: hydrogen peroxide, CP: carbamide peroxide. SD: standard deviation.

significant differences in relation to the initial situation. However, comparing the situation at the end of treatment with the situation one week after, lightness decreased significantly, a* (variation between red and green), displaced significantly towards green with time, $b^{*}$ (variation between yellow and blue), displaced towards blue and $\Delta \mathrm{E}^{*}$ dropped by two units from the end of treatment until one week later. Shade tab changes increased from the end of treatment until one week after treatment from 5.4 to 7.1 . Bleaching percentage increased significantly $(\mathrm{p}=0.016)$ from end of treatment to the measurement taken one week later.

For group B, L* increases significantly at the end of treatment and remained significantly higher one week afterwards in comparison to the initial point, whereas between the end moment and one week after treatment there are no significant differences. $\mathrm{a}^{*}$ tends to displaced towards red significantly between the end of treatment and one week later whereas $b^{*}$ displaces significantly towards yellow. $\Delta \mathrm{E}^{*}$ is higher after one week but the- re are no significant differences in relation to the data obtained immediately after the treatment. The same occurs with bleaching percentages.

Table 3 is a comparison of both study groups. At the start, both groups showed no significant differences in $\mathrm{L}^{*}, \mathrm{a}^{*}, \mathrm{~b}^{*}$. It was observed that $\Delta \mathrm{L}^{*}, \Delta \mathrm{a}^{*}, \Delta \mathrm{b}^{*}$, are significantly different in both groups at the end of treatment and one week later. Group A (CP) was found to achieve greater lightning at the end of treatment and one week later; group $\mathrm{A}$ achieved 3 scores more $\Delta \mathrm{E}$ than group $\mathrm{B}$ in the comparison between the end of treatment and one week later. Shade tab changes and bleaching percentage one week after finalizing the treatment was significantly higher for the group treated with $\mathrm{CP}$ than for the group treated with HP.

\section{Discussion}

Two chemically activated bleaching agents were chosen (one based on HP and the other on CP) in order to eliminate the influence of other factors such as light or other 
activation methods. In both cases, it was attempted to use a procedure similar to that used in-office with these products.

The HP used in the study is presented in a double syringe with a self mixing vial, which improves stability of the active agent and favors appropriate handling with a homogenous mix of the components. The concentrations chosen were: $22 \%$ for CP and $37.5 \%$ for HP; both are the highest percentages within the range of concentrations used in clinical procedures in-office and at-home. Recently published studies report that concentrations between 10 and 30\% showed no significant differences in terms of short-term bleaching capacity, although higher concentrations are recommended for short treatment periods (20), as in our study.

Colour change was evaluated firstly using CIELAB $\mathrm{L}^{*} \mathrm{a}{ }^{*} \mathrm{~b}$ parameters to provide an objective measurement of colour change (21) and secondly, the equivalences given by the spectrophotometer for Vita Classical guide values, more understandable from a clinical perspective. The definitive record was taken one week after treatment had ended in order to evaluate the stabilized colour (because colour can show changes during the first week after having finish the treatment) (22).

$\Delta \mathrm{E}$ assessment made it possible to establish colour differences before and after treatment. Under experimental conditions, the human eye can perceive $\Delta \mathrm{E}$ of 1 or higher (23) but under clinical conditions differences must be 3.7 or above to be detectable (24) However, equal values of $\Delta \mathrm{E}$ can correspond to different degrees of colour perception, so $\Delta \mathrm{E}$ is not a valid indicator for comparing different teeth. $\Delta \mathrm{E}$ does make it possible, however, to follow the evolution of colour in each tooth in a convenient, simple way, thus making it a suitable indicator for this purpose (16). In our study, based on teeth which showed no significant differences in $\Delta \mathrm{E}$ at the start of the study, $\Delta \mathrm{E}$ higher than values acceptable under clinical conditions in both groups were achieved, both at the end of treatment and one week later. We observed, however, that comparing the situation at the end of treatment and a week later, in both groups, there was a significant 10 and 7.20 point decrease (groups A and B, respectively).

In a study by Mokhlis et al., which evaluated CP at a similar concentration to that used in this study two weeks after treatment with custom trays and 20\% CP (Opalescence $20 \mathrm{PF}$, Ultradent Products Inc.), $\Delta \mathrm{E}$ was 9.22 and 7.67 at the end of the treatment and two weeks after treatment had finished, respectively (25). In our study, with a similar concentration in CP and a treatment time of 21 hours, $\Delta \mathrm{E}$ values at the end of treatment and one week later were 19.96 and 9.85 respectively. It must be taken into account that our study was carried out in vitro, which could modify the capacity of free radicals to penetrate the dental structures and therefore these results may be influenced by the different conditions of the treated teeth (26).
In vivo study by Zekonis et al. (17) managed two bleaching techniques: two in-office sessions with 3 x $10 \mathrm{mi}-$ nute applications of a 35\% HP bleaching product (Star Brite, Interdent Inc.) and two weeks at-home treatment with custom trays with a $10 \% \mathrm{CP}$ bleaching product (Opalescence 10, Ultradent Products Inc.). $\Delta \mathrm{E}$ of 5.32 were achieved after in-office treatment and 4.331 one week after treatment had finished, 12.32 when at-home treatment finished and 7.83 one week later. In our study also higher values of $\Delta \mathrm{E}$ were observed with $\mathrm{CP}$ than with HP both when treatment ended and one week later (19,96 / 9,85 CP; 12,40/5,20 HP).

\section{Conclusion}

Under our study conditions, both $22 \% \mathrm{CP}$ and $37.5 \%$ HP were effective for bleaching teeth. Greater bleaching effect was achieved both at the end of treatment and one week later with CP. 3 unit differences in $\Delta \mathrm{E}$ were found between the values obtained at the end of treatment and one week later, within the range of imperceptible to the human eye under clinical conditions.

\section{References References with links to Crossref-DOI}

1. Buchalla W, Attin T. External bleaching therapy with activation by heat, light or laser--a systematic review. Dent Mater. 2007;23:58696.

2. Perdigão J, Baratieri LN, Arcari GM. Contemporary trends and techniques in tooth whitening: a review. Pract Proced Aesthet Dent. 2004;16:185-92.

3. Al Shethri S, Matis BA, Cochran MA, Zekonis R, Stropes M. A clinical evaluation of two in-office bleaching products. Oper Dent. 2003;28:488-95.

4. Auschill TM, Hellwig E, Schmidale S, Sculean A, Arweiler NB. Efficacy, side-effects and patients' acceptance of different bleaching techniques (OTC, in-office, at-home). Oper Dent. 2005;30:156-63.

5. Hasson H, Ismail AI, Neiva G. Home-based chemically-induced whitening of teeth in adults. Cochrane Database Syst Rev. 2006;4:CD006202.

6. Haywood VB. Frequently asked questions about bleaching. Compend Contin Educ Dent. 2003;24:324-38.

7. Li Y, Lee SS, Cartwright S, Wilson AC, DeVizio W, Petrone M, et al. Comparative tooth whitening efficacy of $18 \%$ carbamide peroxide liquid whitening gel using three different regimens. J Clin Dent. 2004;15:11-6.

8. Matis BA. Tray whitening: what the evidence shows. Compend Contin Educ Dent. 2003;24:354-62.

9. Ferrari M, Kugel G, Cagidiaco MC, Barker ML, Gerlach RW. Clinical trial evaluating the peroxide concentration response of whitening strips over 28 days. Am J Dent. 2004;17:291-4.

10. Myers ML, Browning WD, Downey MC, Hackman ST. Clinical evaluation of a $3 \%$ hydrogen peroxide tooth-whitening gel. J Esthet Restor Dent. 2003;15:50-5.

11. American Dental Association (2006) ADA Acceptance Program Guidelines Dentist dispensed home-use toothbleaching products ADA Council on Scientific Affairs. Retrieved online Jul 15, 2009 from: http://www.ada.org/ada/seal/standards/guide_home_bleach. pdf.

12. Braun A, Jepsen S, Krause F. Spectrophotometric and visual evaluation of vital tooth bleaching employing different carbamide peroxide concentrations. Dent Mater. 2007;23:165-9.

13. Kihn PW, Barnes DM, Romberg E, Peterson K. A clinical evaluation of 10 percent vs. 15 percent carbamide peroxide tooth-whitening agents. J Am Dent Assoc. 2000;131:1478-84. 
14. Ritter AV, Leonard RH Jr, St Georges AJ, Caplan DJ, Haywood VB. Safety and stability of nightguard vital bleaching: 9 to 12 years post-treatment. J Esthet Restor Dent. 2002;14:275-85.

15. Powell LV, Bales DJ. Tooth bleaching: its effect on oral tissues. J Am Dent Assoc. 1991;122:50-4.

16. Plotino G, Buono L, Grande NM, Pameijer CH, Somma F. Nonvital tooth bleaching: a review of the literature and clinical procedures. J Endod. 2008;34:394-407.

17. Zekonis R, Matis BA, Cochran MA, Al Shetri SE, Eckert GJ, Carlson TJ. Clinical evaluation of in-office and at-home bleaching treatments. Oper Dent. 2003;28:114-21.

18. CIE (Commission Internationale de l'Eclairage). Colorimetry technical report. CIE Pub. No. 15, 3th ed. Vienna: Bureau Central de la CIE; 2004.

19. Luo W, Westland S, Brunton P, Ellwood R, Pretty IA, Mohan N. Comparison of the ability of different colour indices to assess changes in tooth whiteness. J Dent. 2007;35:109-16.

20. Sulieman M, MacDonald E, Rees JS, Newcombe RG, Addy M. Tooth bleaching by different concentrations of carbamide peroxide and hydrogen peroxide whitening strips: an in vitro study. J Esthet Restor Dent. 2006;18:93-100.

21. Tung FF, Goldstein GR, Jang S, Hittelman E. The repeatability of an intraoral dental colorimeter. J Prosthet Dent. 2002;88:585-90.

22. Matis BA, Cochran MA, Wang G, Eckert GJ. A clinical evaluation of two in-office bleaching regimens with and without tray bleaching. Oper Dent. 2009;34:142-9.

23. Seghi RR, Hewlett ER, Kim J. Visual and instrumental colorimetric assessments of small color differences on translucent dental porcelain. J Dent Res. 1989;68:1760-4.

24. Johnston WM, Kao EC. Assessment of appearance match by visual observation and clinical colorimetry. J Dent Res. 1989;68:81922 .

25. Mokhlis GR, Matis BA, Cochran MA, Eckert GJ. A clinical evaluation of carbamide peroxide and hydrogen peroxide whitening agents during daytime use. J Am Dent Assoc. 2000;131:1269-77.

26. Sulieman M, Addy M, MacDonald E, Rees JS. The effect of hydrogen peroxide concentration on the outcome of tooth whitening: an in vitro study. J Dent. 2004;32:295-9. 